\section{Tree Nuts: Composition, Phytochemicals, and Health Effects}

by Cesarettin Alasalvar and Fereidoon Shahidi (Eds.): CRC Press, Boca Raton, FL, USA, 2009, pp 340, ISBN 978-0-84933735-2. Price: USD 161.96, EUR 143.99

This is the ninth in a series concerning Nutraceutical Science and Technology. The nuts covered are almond (Prunus dulcis), brazil (Bertholletia excelsa), cashew (Anacardia occidentale), hazel (Corylus avellana), macadamia (Macadamia spp), pecan (Carya illinoinensis), pine (Pinus spp), pistachio (Pistacia vera), walnut (Juglans regia), chestnut (Castanea spp) and heart nut (Juglans ailanthifolia). Peanut is not covered in detail but is mentioned for comparison purposes, whilst the chemical compositions of acorn nut (Quercus spp), beech nut (Fagus spp), coconut (Cocos nucifera) and hickory (Carya spp) are listed.

Tree nuts are not harvested in huge quantities but their world production figures for $2006 / 2007$ range from 683,286 metric tons of almonds to 14,880 metric tons for pine nuts. The value of pistachio nuts produced in California has risen from almost zero in 1976 to $\$ 333$ million in 2002.

The first seven chapters deal with the nuts as a group, where comparisons can be made in dealing with health benefits, allergens, sphingolipids, antiaflatoxigenic activity and flavour. Each of the remaining chapters deals with an individual nut species.

The book is anything but light reading; each chapter is packed with data on the composition of minerals, vitamins, amino acids, sugars, organic acids, phenolics, fatty acids and lipid classes. In dealing with the nuts in this fashion there tends to be a bit of repetition in most chapters as each author feels the need to make the chapter free standing. The authors point out that nuts were thought to be unhealthy for many years but that recent research has shown that they confer considerable health benefits. However one of the features of this sort of book is that the evidence from large cohort health studies is hard to come by.
The authors (some 41 authors from 8 countries) are careful in many instances to suggest that more research is needed before health claims can be confirmed. Thus they say that "the Food and Drug Administration promulgated a qualified health claim for tree nuts that eating $1.5 \mathrm{oz}$ of nuts daily as part of a diet low in saturated fat and cholesterol may reduce the risk of heart disease". They also quote "phytates may reduce the risk of colon cancer by reducing oxidative stress".

The authors believe that the book will be of interest to biochemists, chemists, food scientists, nutritionists and health professionals. Whilst I am sure that the book will be of use to graduates in industry, academia and government laboratories, I do not think that many undergraduate students will put it at the top of their shopping list. The book is well presented with few printing errors and the formulae and illustrations are clear. Each chapter has a good list of up-to-date references whilst the overall index is good.

R. J. Hamilton 